\title{
BMJ Open Epidemiology of psoriasis and palmoplantar pustulosis: a nationwide study using the Japanese national claims database
}

\author{
Kiyoshi Kubota, ${ }^{1,2}$ Yukari Kamijima, ${ }^{1,2}$ Tsugumichi Sato, ${ }^{1,3}$ Nobuhiro Ooba, , \\ Daisuke Koide, ${ }^{5}$ Hajime lizuka, ${ }^{6}$ Hidemi Nakagawa ${ }^{7}$
}

To cite: Kubota $\mathrm{K}$, Kamijima Y, Sato T, et al. Epidemiology of psoriasis and palmoplantar pustulosis: a nationwide study using the Japanese national claims database. BMJ Open 2015;5: e006450. doi:10.1136/ bmjopen-2014-006450

- Prepublication history and additional material is available. To view please visit the journal (http://dx.doi.org/ 10.1136/bmjopen-2014006450).

Received 23 August 2014 Revised 31 December 2014 Accepted 5 January 2015

CrossMark

For numbered affiliations see end of article.

Correspondence to Dr Kiyoshi Kubota; kubotape-tky@umin.net

\section{ABSTRACT}

Objective: The primary objective was to estimate the national prevalence of psoriasis and palmoplantar pustulosis (PPP) in Japan. Secondary objectives were to determine (1) whether psoriasis and PPP disease activity varies by season, and (2) whether disease severity is associated with concurrent diabetes mellitus, hyperlipidaemia and hypertension.

Settings: Patients with a psoriasis or PPP diagnosis code between April 2010 and March 2011 were identified using a Japanese national database.

Participants: 565903 patients with psoriasis or PPP were identified. No patient was excluded.

Primary and secondary outcome measures: National prevalence was calculated using census data. We estimated the difference in the proportion of patients who used healthcare services, as a proxy for disease activity, between the hot and cold seasons and the difference in the standardised prevalence of comorbidities between severe and mild disease. The measures were estimated separately for the two broad disease categories of psoriasis and PPP but not in all patients as planned because the two disease categories had major differences.

Results: The national prevalence of psoriasis and PPP was $0.34 \%(95 \% \mathrm{Cl} 0.34 \%$ to $0.34 \%$ ) and $0.12 \%$ $(0.12 \%$ to $0.12 \%)$, respectively. The difference in the proportion of patients who used healthcare services in the hot compared to the cold season was $-0.3 \%$ $(-0.5 \%$ to $-0.1 \%)$ for psoriasis and $10.0 \%(9.8 \%$ to $10.3 \%)$ for PPP. The difference in the standardised prevalence between severe and mild psoriasis was $3.1 \%(2.7 \%$ to $3.4 \%), 3.2 \%$ (2.8\% to $3.6 \%)$ and $5.1 \%$ $(4.7 \%$ to $5.6 \%)$ for concurrent diabetes mellitus, hyperlipidaemia and hypertension, respectively. No significant difference in the prevalence of comorbidity was observed for PPP.

Conclusions: The national prevalence, seasonal variation in disease activity and prevalence of comorbidities in Japanese patients with psoriasis and PPP estimated in this descriptive study may be used as basic information for future studies.

\section{Strengths and limitations of this study}

- This study estimated the national prevalence of psoriasis and palmoplantar pustulosis (PPP) using a national database covering more than $90 \%$ of the Japanese population.

- Seasonal variation in the use of healthcare services (as a proxy for disease activity), as well as psoriasis and PPP treatments and the prevalence of concurrent diabetes mellitus, hyperlipidaemia and hypertension are also examined.

- The main limitation of the current study is that psoriasis and PPP diagnosis codes have not been validated.

- Psoriasis and PPP may have been misclassified by non-specialists, thus affecting our results.

\section{INTRODUCTION}

Psoriasis is a chronic immune-mediated disease affecting $2-4 \%$ of population in the USA and Europe, ${ }^{1-3}$ but has a lower prevalence in Asian countries according to recent epidemiological studies. ${ }^{45}$ The prevalence in Asia of palmoplantar pustulosis (PPP), first described as a variant of pustular psoriasis ${ }^{6}$ and regarded as a rare disease in the West, ${ }^{7}$ is not known.

Databases, including claims databases, have sometimes been used to study the epidemiology of diseases including psoriasis. ${ }^{1} \quad{ }^{4}$ A Japanese universal multi-payer healthcare system covering most citizens was set up in 1961, while the Japanese national database of health insurance claims (JNDB) was only recently established by the Ministry of Health, Labour and Welfare. Since April 2009, the JNDB has collected data for all claims in electronic format. In 2011, the JNDB was made available on a trial basis for research and other secondary purposes. In this descriptive epidemiological study, we used JNDB data to estimate the national prevalence and some 
relevant epidemiological characteristics (including seasonal variation in the use of healthcare services $)^{8}$ of psoriasis and PPP in the Japanese population.

\section{MATERIALS AND METHODS}

\section{Acquisition of claims data}

All patients assigned psoriasis or PPP diagnosis codes in outpatient or inpatient claims issued in electronic format between April 2010 and March 2011 were identified. Overall, $97.9 \%$ and $99.6 \%$ of claims issued from hospitals, $76.0 \%$ and $91.2 \%$ issued from clinics and $99.9 \%$ and 99.9\% issued from community pharmacies from April 2010 to March 2011 were in electronic format. In August $2010,89.5 \%$ of claims from clinics were already in electronic format. ${ }^{9}$ We selected all standardised domestic diagnosis codes mapped to L400-L409 of the 10th Revision of the International Statistical Classification of Diseases and Related Health Problems (ICD-10) in the master table of diagnosis codes for claims in electronic format maintained by the Medical Information System Development Center, Tokyo, Japan. Two identifiers (ID1 and ID2) are assigned to all claims for each patient. These identifiers were created for the JNDB because social security numbers or other unique identifiers are not used in the Japanese healthcare system. ID1 is generated by encrypting the combination of health card number assigned by each insurer, and the patient's date of birth and sex, while ID2 is generated by encrypting the combination of name, date of birth and sex. ID1 may be useful for identifying a patient when their family name has changed (eg, on marriage), while ID2 may be useful for identifying a patient previously insured by a different company (eg, due to job change). Data on sex and age group (in 5-year intervals of $0-4,5-9, \ldots, 80-84$, and 85 years of age or older) were collected. We obtained the diagnosis codes of concurrent diabetes mellitus, hyperlipidaemia and hypertension, the codes of drugs used to treat these conditions, and the codes of drugs and phototherapy used to treat psoriasis and PPP. In the Japanese health insurance system, only one outpatient claim and/ or one inpatient claim from one hospital or clinic are issued for any one patient each month. Similarly, only one claim from one community pharmacy is issued for any one patient each month. We obtained the dates (year and month) of claims issued for the study subjects together with the diagnosis and treatment codes. We also collected information on the specialty of the hospital or clinic department mentioned in claims, although this information is not required for reimbursement and is often not available.

The study was approved by the ethics committee of the Graduate School and Faculty of Medicine, University of Tokyo in October 2011 (no. 3586).

\section{Statistical analysis}

The prevalence of psoriasis and PPP in Japan was estimated by dividing the number of patients with a psoriasis or PPP diagnosis code by the size of the population according to the census of October 2010. The normal approximation CI of the prevalence was also estimated. A total of 21 local diagnosis codes were classified into the following eight disease subclasses: (1) plaque psoriasis ('psoriasis vulgaris' (L400), 'psoriasis' (L409), 'psoriasis vulgaris of entire body' (L400), 'psoriasis of extremities' (L400), 'psoriasis vulgaris of extremities' (L400), 'psoriasis vulgaris of lower back' (L400) and 'plaque psoriasis' (L400)); (2) scalp psoriasis ('seborrheic psoriasis' (L400) and 'psoriasis vulgaris of scalp' (L400)); (3) guttate psoriasis (L404); (4) psoriatic arthritis ('psoriatic arthritis' (L405), 'psoriatic arthritis mutilans' (L405) and 'psoriatic spondylitis' (L405)); (5) pustular psoriasis ('pustular psoriasis' (L401), 'impetigo herpetiformis' (L401), 'acrodermatitis continua' (L402), 'generalised pustular psoriasis' (L401) and 'acute generalised pustular psoriasis' (L401)); (6) erythrodermic psoriasis (L408); (7) palmoplantar pustulosis (L403); and (8) pustulotic arthro-osteitis (PAO) (L403). Patients were further broadly classified into 'patients with PPP' when they had a diagnosis code of PPP or PAO but no other diagnosis code. Otherwise, patients were classified into 'patients with psoriasis'. These two broad disease categories were used on an ad hoc basis because the number of patients with PPP was much larger than expected and the patients in the two disease categories were found to have several important differences. We used the midpoint of the 5-year interval (eg, 37 years old for age group 35-39) to calculate average age.

To estimate seasonal variation in the use of healthcare services for psoriasis and PPP, as a proxy for disease activity, we counted the number of patients in each month during the 12-month observation period for whom an outpatient or inpatient claim with psoriasis or PPP diagnosis code was issued. Patients were then divided into four groups according to the combination of two dummy variables, $\mathrm{X}$ and $\mathrm{Y}$, where the values were assigned as follows: $\mathrm{X}=1$ if the patient used healthcare services for psoriasis or PPP in the hottest season (July or August 2010), while $\mathrm{X}=0$ otherwise; and $\mathrm{Y}=1$ if the patient used healthcare services in the coldest season (January or February, 2011), while $\mathrm{Y}=0$ otherwise. We estimated the difference (and its 95\% CI) between the mean of $\mathrm{X}$ (the proportion of patients who used the service in the hottest season) and the mean of $Y$ (the proportion of patients who used the service in the coldest season) and the difference was tested by the paired $\mathrm{t}$ test.

Treatments for psoriasis and PPP were classified as systemic therapy (adalimumab, infliximab, ustekinumab, methotrexate, ciclosporin and etretinate), phototherapy and topical therapy (topical vitamin D and topical corticosteroid). To determine the distribution of treatments for psoriasis and PPP, the number of patients receiving each treatment was counted, and the proportion of males and the average age were calculated for each treatment group. In addition, for each therapy, the 
proportion of patients with psoriatic arthropathy in the broad category of psoriasis and with PAO in the broad category of PPP was calculated to determine which treatment was preferred for patients with arthropathy.

To examine whether concurrent diabetes mellitus, hyperlipidaemia and hypertension are more frequent in patients with severe psoriasis and PPP, treatment for psoriasis and PPP was used as a surrogate for psoriasis and PPP severity. Patients were subdivided into severity classes I-IV: patients receiving one or more systemic therapies (class I); patients receiving phototherapy but no systemic therapy (class II); patients receiving topical therapy only (class III); and patients receiving no treatment for psoriasis or PPP (class IV). Patients were determined to have diabetes mellitus if they had a diabetes mellitus diagnosis code in at least one claim as well as codes for antidiabetic drugs in claims issued in two or more months during the 12-month observation period. Similarly, patients were defined as having hyperlipidaemia and hypertension, respectively, if they had a related diagnosis code in at least one claim as well as codes for drug treatments (ie, lipid-lowering drugs and anti-hypertensive drugs, respectively) in claims issued in two or more months. The prevalence of diabetes mellitus, hyperlipidaemia and hypertension in each psoriasis and PPP severity class was standardised to the distribution of age and sex in the entire study population. Differences in the standardised prevalence and its $95 \%$ CI were estimated using severity class III as reference. The standard textbook ${ }^{10}$ was used to calculate the difference in the standardised prevalence and its $95 \%$ CI (see equation (15-4) and the 'parallel formula' to equation $(15-10)$, respectively, in reference $\left.{ }^{10}\right)$.

To determine who provided the healthcare service, we obtained the specialty of the department connected to a claim with a psoriasis or PPP diagnosis code. Patients were subdivided into the following three department subgroups: (A) 'dermatology or rheumatology patients' when the department was specified as either dermatology or rheumatology in at least one claim with a psoriasis or PPP diagnosis code; (B) 'patients of an other specialty' when the department was specified as other specialty in at least one claim but not as dermatology or rheumatology in any claim; and $(\mathrm{C})$ "patients of a department not specified' when the department was not specified in any claim. Demographic and other characteristics of patients with psoriasis and PPP examined in each of the three department subgroups are shown in the online supplementary tables.

All statistical analyses were conducted using SAS (V.9.3, SAS Institute, Cary, North Carolina, USA).

\section{RESULTS \\ Prevalence of psoriasis and PPP, and demographic characteristics of patients}

We identified 565903 patients with psoriasis or PPP from a total of 681827 ID1s and 778767 ID2s assuming that identical ID1 and ID2 pairs represented the same patient. As the total population in the October 2010 census was 128 million, 565903 represents a prevalence of $0.44 \%(95 \%$ CI $0.44 \%$ to $0.44 \%)$. The 565903 patients were broadly classified into 429679 patients with psoriasis (national prevalence $0.34 \%, 95 \%$ CI $0.34 \%$ to $0.34 \%$ ) and 136224 patients with PPP. Because 12663 patients classified under the broad category of psoriasis also had a PPP or PAO diagnosis code, 148887 patients (national prevalence $0.12 \%, 95 \%$ CI $0.12 \%$ to $0.12 \%$ ) had a PPP or PAO diagnosis code. The 12663 patients with psoriasis and PPP diagnosis codes accounted for $2.9 \%$ of the 429679 with a psoriasis diagnosis code and $8.5 \%$ of the 148887 with PPP or PAO code. Table 1 shows the age and sex distribution of patients with psoriasis and PPP. In patients with psoriasis, about $60 \%$ were male (male to female ratio: 1.44 ) and average age was 56.7 years, while in patients with PPP, about two thirds were female (male to female ratio: 0.53 ) and average age was 55.5 years. Figure 1 shows the national prevalence of psoriasis and PPP in males and females estimated using the census data. For both males

Table 1 Age and sex distribution of patients with psoriasis and PPP in the JNDB

\begin{tabular}{|c|c|c|c|c|c|c|}
\hline \multirow[b]{3}{*}{ Age (years) } & \multicolumn{3}{|c|}{ Psoriasis* } & \multicolumn{3}{|l|}{ PPP } \\
\hline & \multicolumn{3}{|c|}{$\mathbf{N}$} & \multicolumn{3}{|l|}{$\mathbf{N}$} \\
\hline & Male & Female & Total & Male & Female & Total \\
\hline $0-9$ & 3376 & 3177 & 6553 & 396 & 382 & 778 \\
\hline $10-19$ & 4430 & 5046 & 9476 & 689 & 923 & 1612 \\
\hline 20-29 & 9800 & 9904 & 19704 & 1821 & 3673 & 5494 \\
\hline $30-39$ & 27915 & 22251 & 50166 & 5049 & 9388 & 14437 \\
\hline $40-49$ & 34637 & 21588 & 56225 & 7256 & 13237 & 20493 \\
\hline $50-59$ & 44963 & 28146 & 73109 & 10318 & 23157 & 33475 \\
\hline $60-69$ & 59510 & 33907 & 93417 & 12384 & 23021 & 35405 \\
\hline 70-79 & 48072 & 30930 & 79002 & 7070 & 11559 & 18629 \\
\hline $80-$ & 21070 & 20957 & 42027 & 2265 & 3636 & 5901 \\
\hline Total & 253773 & 175906 & 429679 & 47248 & 88976 & 136224 \\
\hline
\end{tabular}

${ }^{\star}$ Patients with both psoriasis and PPP diagnosis codes are classified as having psoriasis.

JNDB, Japanese national database of health insurance claims; PPP, palmoplantar pustulosis. 
Figure 1 Prevalence of psoriasis and palmoplantar pustulosis (PPP) in the Japanese population. The prevalence of psoriasis and PPP in Japan was estimated by dividing the number of patients with a psoriasis or PPP diagnosis code by the size of the population according to the census of October 2010.

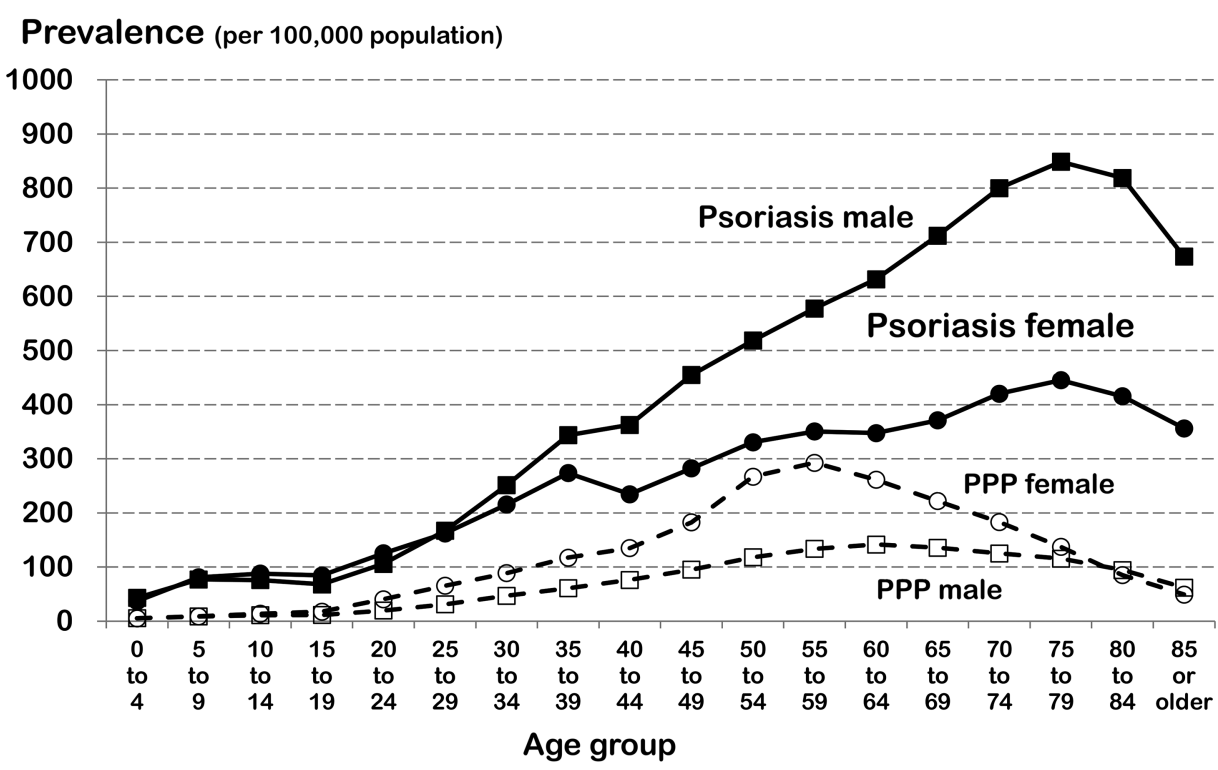

Prevalence (per 100,000 population)

and females, the 75-79-year-old age group had the highest prevalence of psoriasis, while the 55-59-year-old age group for females and the 60-64-year-old age group for males had the highest prevalence of PPP. The demographic characteristics of patients in the three department subgroups of A (dermatology/rheumatology), B (other specialty) and C (not specified) are shown in online supplementary table S1. Of a total of 429679 patients with psoriasis, 132189 (30.8\%), 33763 (7.9\%) and 263727 (61.4\%) were classified into subgroups A, B and $\mathrm{C}$, respectively. Of a total of 136224 patients with PPP, 24195 (20.0\%), 12411 (9.1\%) and 96618 (70.9\%) were classified into subgroups A, B and C, respectively. The male to female ratio was $1.58,1.33$ and 1.39 for psoriasis and $0.52,0.50$ and 0.54 for PPP and the average age was 58.1, 61.8 and 55.3 years for psoriasis and 57.2, 56.9 and 54.9 years for PPP in subgroups A, B and $\mathrm{C}$, respectively.

\section{Domestic diagnosis codes}

The distribution of domestic diagnosis codes divided into eight diagnosis subgroups is shown in table 2. In patients under the broad category of psoriasis, the proportion of males was below $50 \%$ for guttate psoriasis, pustular psoriasis, PPP and PAO but above $70 \%$ for erythrodermic psoriasis. Patients with guttate psoriasis were younger, while patients with erythrodermic psoriasis were older, than those with other types of psoriasis. In patients under the broad category of PPP, patients with $\mathrm{PAO}$ included more females and were younger than patients without PAO. When patients were divided into the three department subgroups, more than half were in

Table 2 Diagnoses given in claims for patients with psoriasis and PPP in the JNDB

\begin{tabular}{|c|c|c|c|c|c|c|}
\hline Diagnoses & $\mathbf{N}^{*}$ & (\%) & Male & $(\%)$ & Age & (SD) \\
\hline \multicolumn{7}{|l|}{ Psoriasis } \\
\hline Plaque psoriasis & 418705 & $(97.4)$ & 248770 & (59.4) & 56.7 & (18.7) \\
\hline Scalp psoriasis & 2832 & $(0.7)$ & 1682 & (59.4) & 57.2 & (18.1) \\
\hline Guttate psoriasis & 2572 & (0.6) & 1136 & (44.2) & 42.4 & (20.6) \\
\hline Psoriatic arthritis & 8360 & (1.9) & 4431 & (53.0) & 55.5 & (15.1) \\
\hline Pustular psoriasis & 4636 & (1.1) & 2250 & (48.5) & 55.9 & (19.3) \\
\hline Erythrodermic psoriasis & 1610 & $(0.4)$ & 1176 & (73.0) & 60.4 & (17.2) \\
\hline PPP† & 12625 & (2.9) & 4675 & (37.0) & 58.3 & (13.7) \\
\hline $\mathrm{PAO} \dagger$ & 401 & $(0.1)$ & 85 & (21.2) & 53.1 & (12.1) \\
\hline Total & 429679 & (100) & 253773 & (59.1) & 56.7 & (18.7) \\
\hline \multicolumn{7}{|l|}{ PPP } \\
\hline PPP & 135647 & (99.6) & 47063 & (34.7) & 55.5 & (15.5) \\
\hline PAO & 5734 & $(4.2)$ & 1307 & (22.8) & 52.1 & (12.6) \\
\hline Total & 136224 & (100) & 47248 & (34.7) & 55.5 & (15.5) \\
\hline
\end{tabular}

*Each patient is counted once for each diagnosis, so the sums of patients with eight diagnoses for psoriasis and two diagnoses for PPP exceed the total.

†Patients with psoriasis and PPP/PAO diagnosis codes.

JNDB, Japanese national database of health insurance claims; PAO, pustulotic arthro-osteitis; PPP, palmoplantar pustulosis. 


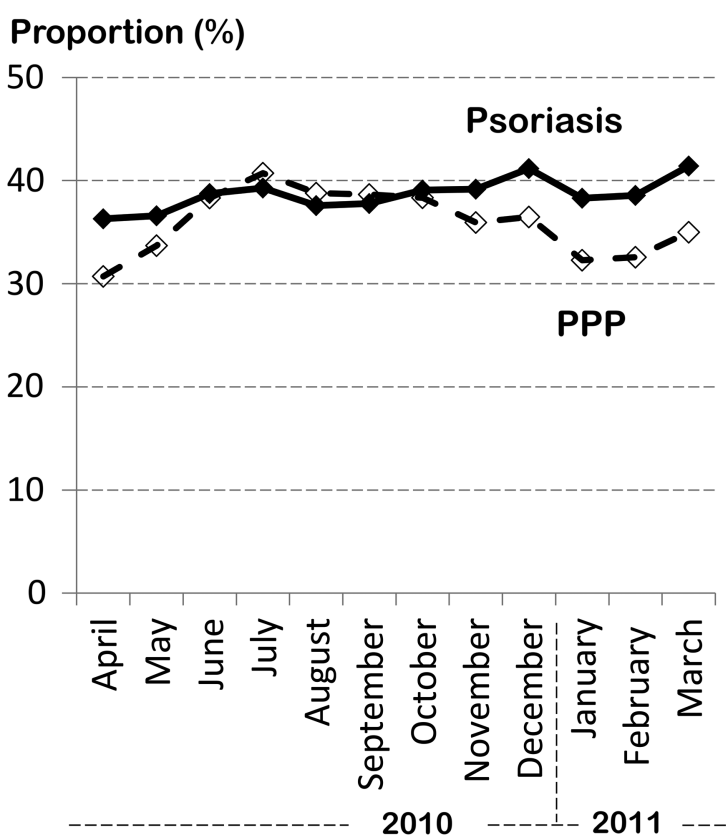

Figure 2 Use of healthcare services by patients with psoriasis and palmoplantar pustulosis (PPP). The proportion was estimated as the number of patients for whom a claim with a psoriasis or PPP diagnosis code was issued in each of the 12 months between April 2010 and March 2011 divided by the number of patients with psoriasis and PPP, respectively.

subclass A (dermatology/rheumatology) for 'pustular psoriasis' (2953/4636), 'erythrodermic psoriasis' (1045/ $1610)$ and 'psoriatic arthritis' (4530/8360) (see online supplementary table S2).

\section{Seasonal variation in the use of healthcare services}

Figure 2 shows the seasonal variation of the use of healthcare services by patients with psoriasis and PPP. On average, about $39 \%$ of patients with psoriasis and $36 \%$ of patients with PPP used healthcare services each month. In patients with psoriasis, the proportion of patients who used healthcare services in the hottest season (July or August, 2010) (52.6\%) was similar to that in the coldest season (January or February, 2011) $(53.0 \%)$, with a difference of only $-0.3 \% \quad(95 \%$ CI $-0.5 \%$ to $-0.1 \%, \mathrm{p}=0.0004)$. On the other hand, in patients with PPP, the proportion of patients who used healthcare services in the hottest season $(55.3 \%)$ was higher than that in the coldest season $(45.3 \%)$, with a difference of $10.0 \%(9.8 \%$ to $10.3 \%, \mathrm{p}<0.0001)$. As shown in online supplementary tables S3 and S4, patients with PPP, but not patients with psoriasis, used healthcare services more during the hottest season, as was observed for all three department subgroups.

\section{Treatments for psoriasis and PPP}

Treatments for psoriasis and PPP are summarised in table 3. Systemic therapies were used mainly for patients with psoriasis, but a few patients with PPP also used etretinate and other systemic therapies. Patients treated with biologics were relatively young and a high proportion had arthropathy. Of 3291 patients with psoriasis on biologic treatment, $2674(81.1 \%)$ were in department subgroup A (dermatology/rheumatology) (see online supplementary table S5). Phototherapy was more frequently used for patients with PPP than with psoriasis, while topical vitamin D was selected more frequently for patients with psoriasis than with PPP. About $80 \%$ of patients with both psoriasis and PPP used topical corticosteroid. About 9\% of patients with psoriasis and about $16 \%$ of patients with PPP received no treatment for psoriasis or PPP. Patients with psoriasis and PPP who received no treatment included more patients with arthropathy when compared receiving those with topical therapy, particularly in department subgroup B (other specialty) (see online supplementary table S5).

\section{Psoriasis and PPP comorbidities}

Table 4 shows the number of patients and standardised prevalence of concurrent diabetes mellitus, hyperlipidaemia and hypertension in severity classes I-III in patients with psoriasis and PPP. For patients with psoriasis, the standardised prevalence was higher in class I (systemic therapy) than in class III (topical therapy only) in the entire population as well as in the three department subgroups (see online supplementary table S6). Prevalence was similar between class II (phototherapy) and class III except for department subgroup A (dermatology/rheumatology), where prevalence was higher in class II than in class III. The prevalence of comorbidities was lower in class IV (no treatment) than in class III in department subgroup A (dermatology/rheumatology) but higher in class IV than in class III in the other department subgroups (see online supplementary table S6). For patients with PPP, there was no significant difference between classes I, II and III.

\section{DISCUSSION}

We determined that during the 12-month period between April 2010 and March 2011, about $0.34 \%$ of patients in the JNDB had a psoriasis diagnosis code and $0.12 \%$ had a PPP diagnosis code. About $60 \%$ of patients with psoriasis were male, while about two thirds of patients with PPP were female. The use of healthcare services was roughly constant during the 12-month observation period in patients with psoriasis, while the use of services by patients with PPP was higher in summer. The prevalence of concurrent diabetes mellitus, hyperlipidaemia and hypertension in patients with psoriasis receiving systemic therapy was higher than in those receiving topical therapy only.

The $0.34 \%$ prevalence of psoriasis demonstrated in our study was lower than the $2-4 \%$ observed in Western countries, while the male predominance in our study contrasted with the almost equal distribution of males and females in Western countries. ${ }^{1-3}$ A low disease prevalence and a predominance of male patients with 


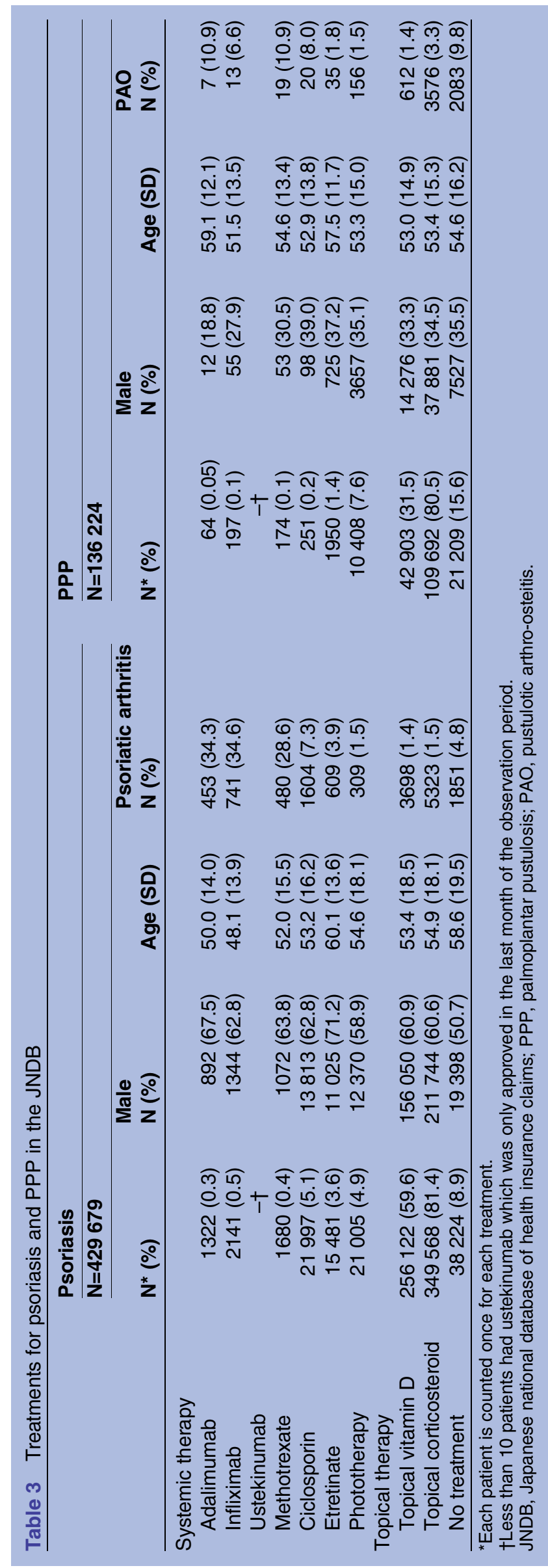

psoriasis were also found in other Asian countries: for example, the prevalence of males and females with psoriasis was $0.23 \%$ and $0.16 \%$ in Taiwan, ${ }^{4}$ and $0.54 \%$ and $0.44 \%$ in China, ${ }^{5}$ respectively. On the other hand, the $0.12 \%$ prevalence of PPP observed in our study was higher than the $0.01-0.05 \%$ found in Western countries, where the female predominance seen in the current study was also observed. $^{711} 12$ Around 20\% of patients with PPP were reported to also have psoriasis, ${ }^{7} 13$ while in our study, $8.5 \%$ of patients with a PPP or PAO diagnosis code also had psoriasis. We observed that the male-to-female ratio differed for psoriasis and PPP, and that psoriasis was more prevalent in the older age groups than PPP. The seasonal variation in the use of healthcare services by patients with PPP, as a proxy of disease activity, was not observed in patients with psoriasis. According to the proposal of the International Psoriasis Council in 2007, PPP should be considered a separate condition from psoriasis. ${ }^{12}{ }^{14}$ However, the findings in the current study indicate there is a relationship between psoriasis and PPP (eg, 8.5\% of patients with psoriasis also had PPP, which is higher than the prevalence of $0.34 \%$ of psoriasis in the whole population), but there are also several differences between psoriasis and PPP, as stated in the above-mentioned proposal.

About $9 \%$ of patients with psoriasis and $16 \%$ of patients with PPP were receiving no treatment for psoriasis or PPP in our study. In a previous study in the UK, one third of patients with psoriasis were not using any therapy at the time of evaluation. ${ }^{1}$ According to a survey conducted in the USA between 2003 and 2011, 49\%, $24 \%$ and $9 \%$ of patients with mild, moderate and severe psoriasis were untreated and approximately about half of all patients were dissatisfied with their treatment. ${ }^{15}$ Likewise, approximately 9\% of patients with psoriasis and $16 \%$ of patients with PPP in our study were receiving no therapy for psoriasis or PPP, while some who were receiving treatment may have been dissatisfied with it. However, some patients may not been receiving psoriasis or PPP therapy because they had very mild disease. Interestingly, as shown in online supplementary table S5, the patient group not receiving psoriasis or PPP treatment included more patients with arthropathy than the group receiving topical therapy, particularly in department subgroup B (other specialty). Thus, severity class IV (no treatment) in department subgroup B might represent more severe psoriasis or PPP than severity class III (topical therapy only), while in other department subgroups, severity class IV might represent less severe psoriasis or PPP when compared to severity class III.

Many studies conducted in Western and Asian countries have reported that the prevalence and incidence of the risk factors for myocardial infarction and stroke such as diabetes mellitus, hyperlipidaemia and hypertension, are high in patients with psoriasis, particularly those with severe psoriasis. ${ }^{16-19}$ The reasons why these risk factors are increased in patients with psoriasis have not been fully explained, but the increased risk may be due to the 
Table 4 Prevalence of diabetes mellitus, hyperlipidaemia and hypertension in three severity classes of patients with psoriasis and PPP in the JNDB

\begin{tabular}{|c|c|c|c|c|c|c|}
\hline & \multicolumn{3}{|l|}{ Psoriasis } & \multicolumn{3}{|l|}{ PPP } \\
\hline & $\begin{array}{l}\text { Class I } \\
\text { Systemic therapy* } \\
\mathrm{N}=39796\end{array}$ & $\begin{array}{l}\text { Class II } \\
\text { Phototherapy† } \\
\mathrm{N}=18833\end{array}$ & $\begin{array}{l}\text { Class III } \\
\text { Topical therapy } \\
\mathrm{N}=332826\end{array}$ & $\begin{array}{l}\text { Class I } \\
\text { Systemic therapy* } \\
\mathrm{N}=2588\end{array}$ & $\begin{array}{l}\text { Class II } \\
\text { Phototherapy } \dagger \\
\mathrm{N}=10153\end{array}$ & $\begin{array}{l}\text { Class III } \\
\text { Topical therapy } \\
\mathrm{N}=102274\end{array}$ \\
\hline \multicolumn{7}{|l|}{ Diabetes mellitus } \\
\hline$N \S$ & 5271 & 1747 & 32378 & 260 & 686 & 7585 \\
\hline Prevalenceף (\%) & 12.7 & 9.0 & 9.6 & 9.3 & 7.7 & 8.5 \\
\hline $\begin{array}{l}\text { Difference }^{* \star}(\%) \\
(95 \% \mathrm{Cl})\end{array}$ & $\begin{array}{l}3.1 \\
\text { (2.7 to } 3.4 \text { ) }\end{array}$ & $\begin{array}{l}-0.6 \\
(-1.0 \text { to }-0.2)\end{array}$ & Ref & $\begin{array}{l}0.8 \\
(-0.5 \text { to } 2.1)\end{array}$ & $\begin{array}{l}-0.8 \\
(-1.4 \text { to }-0.2)\end{array}$ & Ref \\
\hline \multicolumn{7}{|l|}{ Hyperlipidaemia } \\
\hline N§ & 8208 & 3125 & 56561 & 557 & 1731 & 17783 \\
\hline Prevalence $(\%)$ & 20.7 & 16.7 & 17.5 & 18.3 & 17.4 & 17.3 \\
\hline $\begin{array}{l}\text { Difference }{ }^{\star *}(\%) \\
(95 \% \mathrm{Cl})\end{array}$ & $\begin{array}{l}3.2 \\
(2.8 \text { to } 3.6 \text { ) }\end{array}$ & $\begin{array}{l}-0.8 \\
(-1.3 \text { to }-0.3)\end{array}$ & Ref & $\begin{array}{l}1.0 \\
(-0.6 \text { to } 2.6)\end{array}$ & $\begin{array}{l}0.1 \\
(-0.7 \text { to } 1.0)\end{array}$ & Ref \\
\hline \multicolumn{7}{|l|}{ Hypertension } \\
\hline N§ & 11795 & 4369 & 78996 & 576 & 1885 & 19332 \\
\hline Prevalenceף (\%) & 28.5 & 22.8 & 23.4 & 22.4 & 21.8 & 21.7 \\
\hline $\begin{array}{l}\text { Difference }{ }^{\star \star}(\%) \\
(95 \% \mathrm{Cl})\end{array}$ & $\begin{array}{l}5.1 \\
(4.7 \text { to } 5.6)\end{array}$ & $\begin{array}{l}-0.6 \\
(-1.2 \text { to }-0.1)\end{array}$ & Ref & $\begin{array}{l}0.6 \\
(-1.0 \text { to } 2.3)\end{array}$ & $\begin{array}{l}0.04 \\
(-0.9 \text { to } 0.9)\end{array}$ & Ref \\
\hline
\end{tabular}

${ }^{*}$ Patients who received one or more of the systemic therapies listed in table 3.

†Patients with phototherapy but no systemic therapy.

$\ddagger$ Patients with topical vitamin D or topical corticosteroid only.

$\S$ Number of patients with a diagnosis code of concurrent disease (diabetes mellitus, hyperlipidaemia or hypertension) in at least in claim as well as a diagnosis code of drugs to treat the

concurrent disease in claims issued in two or more months.

IPrevalence standardised to the distribution of age and sex in the entire study population of 565903 patients.

${ }^{* *}$ Difference in prevalence compared to class III.

JNDB, Japanese national database of health insurance claims; PPP, palmoplantar pustulosis. 
high prevalence of obesity and other known predisposing factors in patients with psoriasis. ${ }^{20}$ It is also possible that some of the comorbidities are adverse reactions to ciclosporin and other systematic therapies for psoriasis. ${ }^{21}$ In our study, an increase in comorbidity was observed in patients with severe psoriasis but not in patients with severe PPP when compared to patients receiving topical therapy only. Ciclosporin may be a major contributor to the high prevalence of the comorbidity as it was used by over half of the patients with psoriasis receiving systemic therapy but by only $10 \%$ of those with PPP receiving systematic therapy.

The main limitation of the current study is that psoriasis and PPP diagnosis codes have not been validated. Therefore, the true national prevalence may be higher or lower than that reported here. One concern is disease misclassification, particularly when the diagnosis is made by a non-specialist. However, demographic characteristics and other major findings were common to the whole population and department subgroup A (dermatology/rheumatology). This suggests that all patients identified by the claims diagnosis codes in the current study roughly represented all patients with psoriasis and PPP who used healthcare services during the observation period. Nevertheless, we could not exclude some types of misclassification. For instance, the proportion of guttate psoriasis in patients with psoriasis was around $4 \%$ in a previous study from Japan, ${ }^{22}$ and higher than the $0.6 \%$ in the current study (table 2), which could be due to misclassification. The strength of the study is the use of the claims database covering over $90 \%$ of patients nationally.

In conclusion, the study using JNDB data collected from the entire nation revealed that the prevalence of psoriasis was lower and the prevalence of PPP was higher than in Western countries. As in previous studies, severe psoriasis was associated with a high prevalence of concurrent diabetes mellitus, hyperlipidaemia and hypertension. The prevalence and other characteristics of psoriasis and PPP estimated in the current study may provide basic information for future studies.

\author{
Author affiliations \\ ${ }^{1}$ Department of Pharmacoepidemiology, Graduate School of Medicine, \\ University of Tokyo, Tokyo, Japan \\ ${ }^{2}$ NPO Drug Safety Research Unit Japan, Tokyo, Japan \\ ${ }^{3}$ Faculty of Pharmaceutical Sciences, Tokyo University of Science, Chiba, \\ Japan \\ ${ }^{4}$ Department of Clinical Pharmacy, Nihon University School of Pharmacy, \\ Chiba, Japan \\ ${ }^{5}$ Department of Clinical Epidemiology and Systems, Graduate School of \\ Medicine, University of Tokyo, Tokyo, Japan \\ ${ }^{6}$ Department of Dermatology, Asahikawa Medical University, Hokkaido, Japan \\ ${ }^{7}$ Department of Dermatology, Jikei University, School of Medicine, Tokyo, \\ Japan
}

Acknowledgements We thank the Japanese Society for Psoriasis Research which motivated and encouraged us to conduct the current study.

Contributors KK conceived and designed the study, analysed and interpreted the data. and drafted the manuscript. YK analysed and interpreted the data.
TS, NO and DK helped acquire the data and interpreted the data. HI and HN contributed to the conception and design of the study. In addition, all authors carefully reviewed the draft and revised it critically. All authors gave the final approval of the manuscript.

Funding The current study was supported by research funds provided by Janssen Pharmaceutical K.K. which was not involved in the design or conduct of the research, or the analysis, interpretation and publication of the results.

\section{Competing interests None.}

Ethics approval The Ethics Committee of the Graduate School and Faculty of Medicine, University of Tokyo approved this study.

Provenance and peer review Not commissioned; externally peer reviewed.

Data sharing statement No additional data are available.

Open Access This is an Open Access article distributed in accordance with the Creative Commons Attribution Non Commercial (CC BY-NC 4.0) license, which permits others to distribute, remix, adapt, build upon this work noncommercially, and license their derivative works on different terms, provided the original work is properly cited and the use is non-commercial. See: http:// creativecommons.org/licenses/by-nc/4.0/

\section{REFERENCES}

1. Gelfand JM, Weinstein R, Porter SB, et al. Prevalence and treatment of psoriasis in the United Kingdom - a population-based study. Arch Dermatol 2005;141:1537-41.

2. Kurd SK, Gelfand JM. The prevalence of previously diagnosed and undiagnosed psoriasis in US adults-results from NHANES 20032004. J Am Acad Dermatol 2009;60:218-24.

3. Parisi R, Symmons DP, Griffiths CE, et al. Identification and Management of Psoriasis and Associated ComorbidiTy (IMPACT) project team. Global epidemiology of psoriasis-a systematic review of incidence and prevalence. J Invest Dermatol 2013;133:377-85.

4. Chang YT, Chen TJ, Liu PC, et al. Epidemiological study of psoriasis in the National Health Insurance Database in Taiwan. Acta Derm Venereol 2009;89:262-6.

5. Ding X, Wang T, Shen Y, et al. Prevalence of psoriasis in China-a population-based study in six cities. Eur J Dermatol 2012;22:663-7.

6. Barber HW. Acrodermatitis continua vel perstans (dermatitis repens) and psoriasis pustulosa. Br J Dermatol 1930;42:500-18.

7. De Waal AC, Van de Kerkhof PCM. Pustulosis palmoplantaris is a disease distinct from psoriasis. $J$ Dermatolog Treat 2011;22:102-5.

8. Hancox JG, Sheridan SC, Feldman SR, et al. Seasonal variation of dermatologic disease in the USA: a study of office visits from 1990 to 1998. Int J Dermatol 2004;43:6-11.

9. Ministry of Health, Labour and Welfare. [Current status of electronic submission of health care claims and advancement of reimbursement of health care service fee]. 21 Jul 2011. In Japanese. http://www.mhlw.go.jp/stt/shingi/2r9852000001jcmq-att/ 2r9852000001jcu1.pdf (accessed 9 Aug 2014).

10. Greenland S, Rothman KJ. Introduction to stratified analysis. In: Rothman KL, Greenland S, Lash T. eds. Modern epidemiology. 3rd edn. Philadelphia: Lippincott Williams \& Wilkins, 2008:258-82.

11. Asumalahti K, Ameen M, Suomela $S$, et al. Genetic analysis of PSORS1 distinguishes guttate psoriasis and palmoplantar pustulosis. J Invest Dermatol 2003;120:627-32.

12. Brunasso AM, Puntoni M, Aberer W, et al. Clinical and epidemiological comparison of patients affected by palmoplantar plaque psoriasis and palmoplantar pustulosis-a case series study. Br J Dermatol 2013;168:1243-51.

13. Gelfand JM, Neimann AL, Shin DB, et al. Risk of myocardial infarction in patients with psoriasis. JAMA 2006;296:1735-41.

14. Griffiths CE, Christophers E, Barker JN, et al. A classification of psoriasis vulgaris according to phenotype. $\mathrm{Br} J$ Dermatol 2007;168:1243-51.

15. Armstrong AW, Robertson AD, Wu J, et al. Undertreatment, treatment trends, and treatment dissatisfaction among patients with psoriasis and psoriatic arthritis in the United States-findings from the National Psoriasis Foundation surveys, 2003-2011. JAMA Dermatol 2013;149:1180-5.

16. Azfar RS, Seminara NM, Shin DB, et al. Increased risk of diabetes mellitus and likelihood of receiving diabetes mellitus treatment in patients with psoriasis. Arch Dermatol 2012;148:995-1000.

17. Cohen AD, Weitzman D, Dreiher J. Psoriasis and hypertension-a case-control study. Acta Derm Venereol 2010;90:23-6. 
18. Ma C, Harskamp CT, Armstrong EJ, et al. The association between psoriasis and dyslipidaemia - a systematic review. Br J Dermatol 2013;168:486-95.

19. Tsai TF, Wang TS, Hung ST, et al. Epidemiology and comorbidities of psoriasis patients in a national database in Taiwan. J Dermatol Sci 2011;63:40-6.

20. Samarasekera EJ, Neilson JM, Warren RB, et al. Incidence of cardiovascular disease in individuals with psoriasis-a systematic review and meta-analysis. J Invest Dermatol 2013;133:2340-6.

21. Kremers HM, McEvoy MT, Dann FJ, et al. Heart disease in psoriasis. J Am Acad Dermatol 2007;57:347-54.

22. Takahashi H, Nakamura K, Kaneko F, et al; Japanese Society for Psoriasis Research. Analysis of psoriasis patients registered in the Japanese Society for Psoriasis Research from 2002 to 2008. J Dermatol 2011;38:1125-9. 